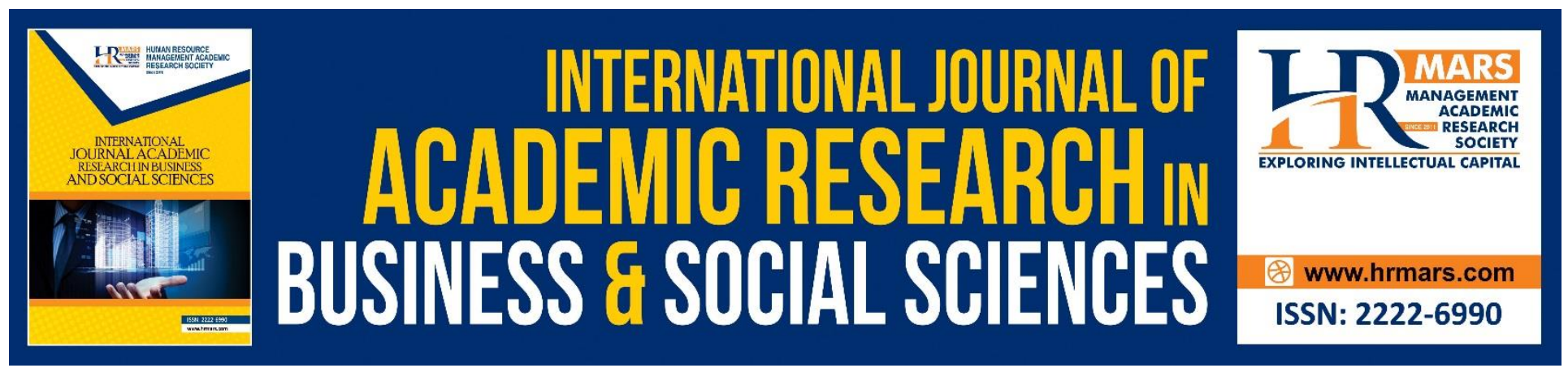

\title{
Effective Academic Leadership: Key Aspects of Leader Behavior in Higher Education
}

Maryam Mahdinezhad, Mahaliza Mansor, Norimah Rmbeli, Emilda Hashim, Mohammad Shahhosseini

To Link this Article: http://dx.doi.org/10.6007/IJARBSS/v8-i9/4646

DOI: $\quad 10.6007 /$ IJARBSS/v8-i9/4646

Received: 06 August 2018, Revised: 06 September 2018, Accepted: 29 September 2018

Published Online: 15 October 2018

In-Text Citation: (Mahdinezhad, Mansor, Rmbeli, Hashim, \& Shahhosseini, 2018)

To Cite this Article: Mahdinezhad, M., Mansor, M., Rmbeli, N., Hashim, E., \& Shahhosseini, M. (2018). Effective Academic Leadership: Key Aspects of Leader Behavior in Higher Education. International Journal of Academic Research in Business and Social Sciences, 8(9), 657-665.

Copyright: (C) 2018 The Author(s)

Published by Human Resource Management Academic Research Society (www.hrmars.com)

This article is published under the Creative Commons Attribution (CC BY 4.0) license. Anyone may reproduce, distribute, translate and create derivative works of this article (for both commercial and non-commercial purposes), subject to full attribution to the original publication and authors. The full terms of this license may be seen

at: http://creativecommons.org/licences/by/4.0/legalcode

Vol. 8, No. 9, September 2018, Pg. 657 - 665

Full Terms \& Conditions of access and use can be found at http://hrmars.com/index.php/pages/detail/publication-ethics 


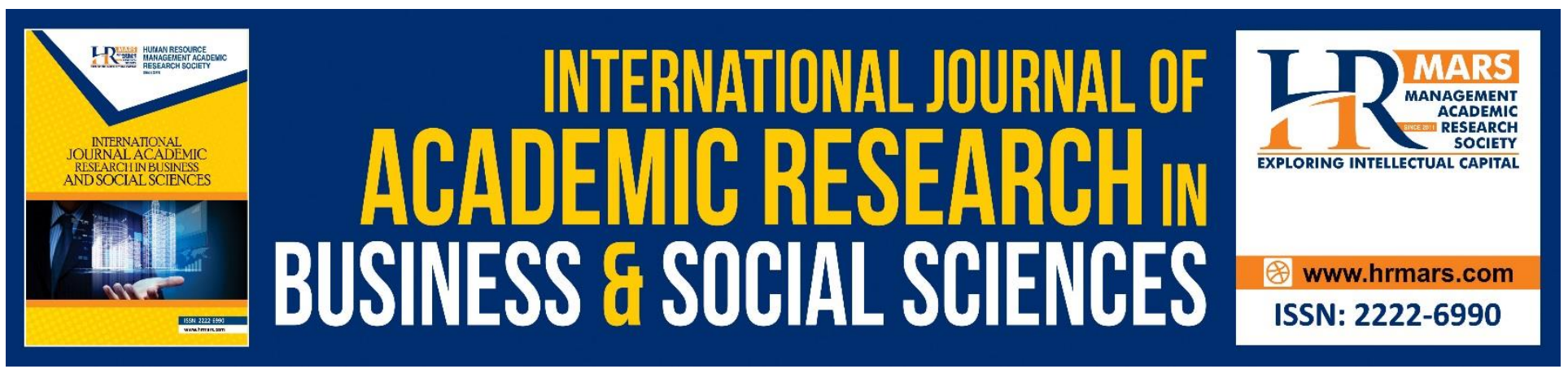

\title{
Effective Academic Leadership: Key Aspects of Leader Behavior in Higher Education
}

\author{
Maryam Mahdinezhad \\ Faculty of Management \& Economics, Sultan Idris Education University, Tanjung Malim, Perak, \\ 35900, Malaysia \\ Mahaliza Mansor \\ Faculty of Management \& Economics, Sultan Idris Education University, Tanjung Malim, Perak, \\ 35900, Malaysia \\ Norimah Rmbeli \\ Faculty of Management \& Economics, Sultan Idris Education University, Tanjung Malim, Perak, \\ 35900, Malaysia \\ Emilda Hashim \\ Faculty of Educational Studies, Universiti Putra Malaysia, 43400 Serdang Selangor, Malaysia \\ Mohammad Shahhosseini \\ Faculty of Management, Payame Noor University, 19395-3697, Tehran, Iran
}

\begin{abstract}
Currently, effective leadership plays an important role in improving the context of higher education. Policy makers, leaders, and university staff considered the effective leadership as determining a factor for management of universities. Although effective leadership is examined by many researchers, to the best of author knowledge, only a few references in the literature systematically reviewed which forms, behaviors of leadership are related to effective leadership in the context of higher education. To fill the gap in the existing literature, this paper aims to examine which aspects of leadership are related to effective leadership in the context of higher education. Moreover, it addresses some effective behaviors of leaders such as strategic vision, encouraging open communication, having credibility for effectively leading and acting as a role model in an educational environment. The findings suggest a direction for future development in effective leadership
\end{abstract}


behaviors which need to be highlighted and identified for representing efficient leadership in the higher education context.

Keywords: Effective Leadership Skills, Leadership Behaviors, Strategic Vision, Open Communication and Higher Education.

\section{Introduction}

The context of leading universities might pose a distinctive challenge, due to its numerous goals, the organizational complexity, and universities' traditional values. Therefore, in higher education, the nature of leadership is complex and questioned (Scott, 2011). A problem arises from this fact that the criteria for making an individual effective as a leader in the context of higher education have not been recognized yet. The lateral approach to leadership study has left researchers questioning how they might predict Effective Academic Leadership Styles, as well as who they might select or promote within an organization. Appropriate subjects to lead this research are to indicate appropriate relationships between personal attribute in a leadership position and effective academic leadership styles. To this point, the identification of effective kind of leadership and leadership behavior in the context of universities as the decision is made based on decisions of experts is a controversial issue. The effective leadership plays a major role in higher education since an effective leader can lead to success by implementing a weak plan, however, a poor leader might lead to failure despite having a proper plan. Due to this fact, the development of effective leadership by utilizing a reliable talent administration plan in the context of higher education can enhance considerable professional significance. Consequently, the present paper is motivated by the need to identify necessary leadership behaviors required for effective leadership in the context of higher education.

Previous studies associated with leadership in higher education had a tendency to emphasize the role of the senior leaders (Altbach, 2010). These senior leaders have interaction with various professionals in the context of higher education; frequently those who have positions utilizing special leadership skills. Since, it is essential to consider all features of being a leader such as autocratic, bureaucratic, transactional, etc. However, within the elements and models of leadership in higher education, transformational leadership has not been highlighted as others. Nowadays, at university level often effective leadership takes away from acting as an autocratic leader and utilizes more transformational leadership which involves collaboration, cooperation.

\section{Leadership Theories}

Leadership theory opposes that individuals' behavior can considerably affect others' behavior. Therefore, an effective leader has the potential to have an effect on others to achieve organizational goals. Burns (1978) developed the most popular and dominant leadership model, and categorized leader's behavior into two type of transactional and transformational.

\section{LEADERSHIP CONTEXT IN HIGHER EDUCATION}

In the context of higher learning education, the roles of senior leader are mainly centered on notions of collegiality, however, this is not well matched with the demand of using resources efficiently and effectively (Davis, 2014). Probably, managerialism in higher education has been increasing, with its 
INTERNATIONAL JOURNAL OF ACADEMIC RESEARCH IN BUSINESS AND SOCIAL SCIENCES

Vol. 8, No. 9, Sept. 2018, E-ISSN: 2222-6990 @ 2018 HRMARS

emphasis on the culture of metrics, audit, policy, flexibility, clarity has led to bewilderment, within higher education sector because of this conflict of cultures and working systems (Feser, Mayol, \& Srinivasan, 2015).

Furthermore, current most senior leaders of institutions encounter with a key challenge. Since as the university has represented externally, senior leaders require to demonstrate the rules of the institution (Altbach, 2010). When institutions make changes based on the needs of globalization, the identity and rules of the institution might require being revised in many cases. Nevertheless, to achieve this goal, leaders with senior executive roles and professionals are demanded to direct the priorities of academic collaborators. If possible, this guidance is achieved through developing the shared beliefs and values to facilitate operating the institution smoothly exclusive of being hindered by bureaucratic organizations (Schafer, 2010), however, the reality is commonly different in higher educational context.

\section{Findings from Literature Review}

\section{Transactional-Transformational Leadership Approach}

In the 1970s, Burns (1978) investigated on reinforcement of performance (transactional behavior), along with apprehending followers and developing their self-worth and focus (transformational behaviors). They put an emphasis on vision, staff engagement competence, experimentation, credibility, values, and judgment (Avolio, Walumbwa, \& Weber, 2009).

In terms of transactional leadership, leaders and followers swap needs and facilities to achieve independent goals, or they form a leadership by exchanging positive reinforcement is provided for good performance (Mahdinezhad \& Yunus, 2017). Some evidence revealed that a charismatic or transformational leadership style might be more associated with the context of education (McCleskey, 2014), or it is suggested that a combination of transformational and transactional styles are efficient for educational setting (Odumeru \& Ifeanyi, 2013).

Over the past 20 years, the paradigm of transformational leadership and transformational behavior has gained increasing attention (Scott, 2011). Leaders are capable to transform the fidelities and behaviors of their staff as a result of shared organizational culture. However negative influences might appear; dialogue among staff might be restrained, problem-solving might reduce and people are observed as the cause of the problems. The pressure on people is suggestive of command-andcontrols' structures and rules. Theory of transformational leadership is associated with the significance of individual leaders, the charisma, and intellectual stimulation (Antonakis, 2012). Additionally, if leaders transform leadership to staff, a dynamic connection to the ideas of other is created to enlighten systematic thinkers. A college administrator can play the role of the transformational leader through incorporating a shared vision of change, enabling voices in a cooperative community and reflecting on vision value (Sadeghi, 2012). 


\section{Vision}

Professionals in context of education are supposed to raise their awareness in terms of clarity and goal. Based on McCleskey ( 2014) the ability of leader for articulating an educational vision plays a major role to develop constant improvement. Moreover, it is necessary for leaders to be must be the superintendents for all to achieve a vision of success. To work in an educational environment with current educational requirements, university administrators must be transparent in expressing their expectations and vision to support change. Therefore, leaders achieve success if they act as facilitators instead of authoritarians. Furthermore, if leaders consult with other professionals' points of view in developing a vision, it will allow individuals to feel empowered, committed, imaginative, risk-taker, and get involved. Moreover, it is evident that sharing an apparent vision or clear target facilitates understanding by determining and evaluating goals and outcomes appropriately. In addition, Schafer (2010) restated that, if the purpose and rationale behind decisions are clearly communicated, the probability of achieving success is very high in an educational context. This integrates collaborating with those who have helped to develop the new vision, which leads to change, and allows individuals to find a solution to meet the needs of students or faculty.

\section{Voices}

Based on Scott (2011) effective leadership is defined as a corporation with others instead of making a decision by a one-person. Moreover, Arnold (2013) has pointed out that in context of higher education effective leaders, guide through team-working in web-like systems which are nonhierarchical. If a leader makes the decision for the successful final product, he is required to consult with all members involved to identify the individuals who can lead to expertise. Besides, if a leader allows for the team-working environment, a collaborative culture is developed. Professionals can benefit from collaborative environments which play a pivotal role in the effectiveness of a leader. This environment strengthens a professional learning community in which forces team- working and interactions, and fosters individuals to work cooperatively towards a shared vision.

\section{Values}

If the levels of team-working and collaboration are high, the overall process and final product of the vision and the value of its outcome will be successful. Based on Odumeru and Ifeanyi (2013) effective leadership needs reflection. To this end, the professional requires being aware of when to be introspective. In the context of higher education, leaders are required to evaluate the consequence of the shared vision to realize whether it effectively has met student's and/or staff's needs or if the challenges still continue. According to Bass and Avolio ( 2013), it is essential that leaders lead and guide their institutes into the future by reflecting critically and understanding profoundly the organizational culture and values. The reflection over values enables the individual to consider the achieved goal, take into account mission, values or university needs, and skillfully review what might be necessary with the aim of forming or creating a more effective vision in the imminent future.

In relation to this, transformational leadership creates team-building in order to learn from each other, form and reflects on shaping visions and goals. Frequently this type of cooperation and relationship make positive change and increases the effectiveness of professional leadership 
INTERNATIONAL JOURNAL OF ACADEMIC RESEARCH IN BUSINESS AND SOCIAL SCIENCES

Vol. 8, No. 9, Sept. 2018, E-ISSN: 2222-6990 @ 2018 HRMARS

practices. Moreover, based on Kim (2014) the transformational model intent to raise capacity development and increase the levels of personal commitment which bring about the extra work and more productively.

\section{Effectively Leading: Other Considerations}

Based on a comprehensive review of the literature, the following characteristics of leader behavior which were related to effective leadership in the context of higher education is discussed consecutively including some demonstrations from the existing literature.

\section{Clear Sense of Direction}

This characteristic denotes that effective leaders provide clear and transparent direction regarding the paths and vision of their institution. These kind of leaders are responsible for a strategic leadership of their institution. Wolverton, Ackerman and Holt (2005) conducted a study on 200 US senior excellent leaders who had been selected as effective leaders. The results of this study revealed that all these leaders shared a common conspicuous characteristic that is they created a shared organizational vision and goals. Furthermore, Benoit and Graham (2005) investigated about 13 leaders who designated as effective and excellent leaders by their followers, all pointed to the significance of the leaders who shared a common vision.

\section{Treating Academic Staff with Integrity}

This characteristic of leader behavior refers to following attributes; being fair to them, having faith in staff, dealing with staff equitably. Bryman (2009) realized if leaders treated staff equitably and fairly, it would be more probable that leader develops and maintain self-esteem. Therefore, one of a vital set of aspects ineffective leadership is that leaders must be able to deal with staff consistently, fairly, inclusively, and responsively.

\section{Being Trustworthy}

This characteristic of leader behavior refers to this requirement that leaders must be reliable, trustworthy with a high level of integrity. This considered as a common theme in the literature of leadership (Bryman, 2009). Trocchia \& Andrus (2003) carried out a study to identify the top characteristics of effective leaders working in marketing departments. They found that integrity, honesty, and fairness were the tope characteristic, and moreover, they revealed that fairness is more associated with the components of effective leadership. Comparably, Bryman (2007b) conducted a study to identify the perceptions of staff towards what are the criteria for effective leadership among heads of department in the higher education context. The data obtained from questionnaires which administered to various groups of deans, fellow heads of department and academic staff. The results revealed that there was a relatively high level of agreement between respondent in different groups. The two criteria of trust and integrity were found to be essential characteristics of effective leaders. Since these characteristics enhance trust and cooperation among members of the organization and 'displays integrity and moral behavior in all circumstances. 


\section{Encouraging Open Communication}

Giving opportunity to be involved in making crucial decisions and creating open communication to discuss the issues of concern are important to effective leadership. The literature frequently establishes its importance for academics. It is much more related to the concept of autonomy among academics since they gain the ability to be responsible for their own work. Czech and Forward (2010) investigated that open communication among faculty and staff' led to the effectiveness of their department. Keith and Buckley (2011) conducted a study to identify distinctive characteristics of leaders among academics, he found that leaders who were open to suggestion and consulted with staff were successful in maintaining of morale among academic leaders.

\section{Acting as a Role Model and Having Credibility}

Typically effective leaders serve as role models for their staff, therefore it is essential for leaders forward to establish credibility as academics. Creswell and Brown (1992) conducted a qualitative study among 33 US academic leaders who had been identified as effective leaders. They recognized several distinct roles that came out of an examining particular participant that the interviewees helped a member of academic staff to develop efficiently. One of these roles was mentorship, which acted as a model for publicizing research activities, sharing knowledge, commenting on others' work in terms of publishing and funding. Based on Benoit and Graham's (2005) research, serving as a role model in leading teaching and research was considered as one of four salient characteristics of the leaders. These findings associated with credibility and role modeling are consistent with Goodall's (2006) research who examined citation patterns. She suggested that it is essential for leaders to have credibility and reliability as researchers as guiding research-oriented universities.

\section{Discussion}

This study has assessed effective leadership skills applied by leaders in the context of higher education. The findings revealed that effective leadership behavior should account for followers, the leader, and the context. Basically, academic leadership differs from business leadership, and entail special capabilities and experience. Nevertheless, at some point, leadership is associated with academic leadership. Therefore, leadership is being perceived and regarded as a member of the academic community. Undoubtedly experienced individuals are able to offer a substantial contribution to the academic setting, to bridge the gap between theory and practice, and present new ideas. Though, they require making progress further than capability and values, towards a proficiency and a clear recognizing the visions.

\section{Conclusion}

This paper intended to investigate the existing literature on effective leadership in the context of higher education. Besides, the findings offer a more comprehensive and empirical perspective on how Effective Academic Leadership Styles was presented in higher learning institutions. The results show that most of academic leaders are contributing leadership roles through utilizing appropriate leadership styles. Additionally, this study identified several characteristics of leader behavior as related to effective leadership. These characteristics include various aspects of leader behavior which more generally are found in the literature of leadership. These aspects are the trustworthy, emphases 
INTERNATIONAL JOURNAL OF ACADEMIC RESEARCH IN BUSINESS AND SOCIAL SCIENCES Vol. 8, No. 9, Sept. 2018, E-ISSN: 2222-6990 @ 2018 HRMARS

on vision, encouraging communication, acting as a model and having credibility. Based on the literature, characteristics of leader behavior which are probably to be important in higher education develop a collegial environment. Furthermore, practically there is some evidence which revealed that effective leadership in higher education regularly does not mean to act as an authoritarian. Rather than leaders are supposed to apply more transformational styles which involve cooperation and consultation. Moreover, leaders need to be clear in articulating their vision, and cooperate with their team and reflect on the value of outcome which all considered as fundamentals of transformational leadership. To this end, leaders should promote their ability to promote the process of effective leading meaningfully and try to adhere to characteristics of effective leaders as represented in this study.

\section{Acknowledgement}

This research is funded by University Pendidikan Sultan Idris (2017-0258-107-01).

\section{Corresponding Author}

Maryam Mahdinezhad, Faculty of Management \& Economics, Sultan Idris Education University, Tanjung Malim, Perak, 35900, Malaysia. Email: Maryam.m@fpe.upsi.edu.my

\section{References}

Altbach, P. G. (2010). Leadership for World-Class Universities. Leadership for World-Class Universities: Challenges for Developing Countries. http://doi.org/10.4324/9780203842171

Antonakis, J. (2012). Transformational and charismatic leadership. The Nature of Leadership, 41(0), 256-288. http://doi.org/10.1016/j-leaqua.2012.05.002

Arnold, T. (2013). Effective leadership. Smart Business St. Louis, 6(5), 5. Retrieved from http://search.ebscohost.com/login.aspx?direct=true \&db=buh\&AN=87493011\&lang=de \&site=e host-live

Avolio, B. J., Walumbwa, F. O., \& Weber, T. J. (2009). Leadership: Current Theories, Research, and Future Directions. Published in Annual Review of Psychology, 60, 421-449. http://doi.org/10.1146/annurev.psych.60.110707.163621

Bass, B. M., \& Avolio, B. J. (2013). Transformational Leadership and Organizational Culture. International Journal of Public Administration, 17(1), 112-121. http://doi.org/10.1080/01900699408524907

Benoit, P., \& Graham, S. (2005). Leadership excellence: Constructing the role of department chair. Academic Leadership, 3(1).

Bryman, A. (2007). Effective leadership in higher education :a literature review. Studies in Higher Education, 32(6), 693-710. http://doi.org/10.1080/03075070701685114

Bryman, A. (2009). Effective leadership in higher education: a literature review. Studies in Higher Education, 32(6), 693-710. http://doi.org/10.1080/03075070701685114

Burns, J. M. (1978). Leadership. In Leadership (pp. 66-75).

Creswell, J. W., \& Brown, M. L. (1992). How chairpersons enhance faculty research: A grounded theory study. The Review of Higher Education, 16(1), 41-62. Retrieved from http://search.proquest.com/docview/1308038491?accountid=8172 
INTERNATIONAL JOURNAL OF ACADEMIC RESEARCH IN BUSINESS AND SOCIAL SCIENCES

Vol. 8, No. 9, Sept. 2018, E-ISSN: 2222-6990 @ 2018 HRMARS

Czech, K., \& Forward, G. L. (2010). Leader Communication: Faculty Perceptions of the Department Chair. Communication Quarterly, 431-457. http://doi.org/10.1080/01463373.2010.525158

Davis, H. (2014). Towards leadingful leadership literacies for higher education management. Journal of Higher Education Policy and Management, 36(4), 371-382. http://doi.org/10.1080/1360080X.2014.916467

Feser, C., Mayol, F., \& Srinivasan, R. (2015). Decoding leadership: What really matters. McKinsey Quarterly, 25(January), 1-4. Retrieved from http://www.mckinsey.com/insights/leading_in_the_21st_century/decoding_leadership_what_ really_matters

Goodall, A. H. (2006). Does it Take an Expert to Lead Experts? An Empirical Study of Business School Deans. Higher Education, (March).

Gunter, H. (2010). Full Range Leadership Development. Educational Management Administration \& Leadership, 38(January 2016), 396-397. http://doi.org/10.1177/1741143210362934

Keith, S. J., \& Buckley, P. F. (2011). Leadership experiences and characteristics of chairs of academic departments of psychiatry. Academic Psychiatry, 35(2), 118-121. http://doi.org/10.1176/appi.ap.35.2.118

Kim, H. (2014). Transformational Leadership, Organizational Clan Culture, Organizational Affective Commitment, and Organizational Citizenship Behavior: A Case of South Korea's Public Sector. Public Organization Review, 14(3), 397-417. http://doi.org/10.1007/s11115-013-0225-z

Mahdinezhad, M., \& Yunus, J. N. (2017). The Association of Leadership Styles and Administrators ' Performance, 7(6), 940-952. http://doi.org/10.6007/IJARBSS/v7-i6/3054

McCleskey, J. A. (2014). Situational, Transformational, and Transactional Leadership and Leadership Development. Journal of Business Studies Quarterly, 5(4), 117. Retrieved from http://ezproxy.leedsmet.ac.uk/login?url=http://search.ebscohost.com/login.aspx?direct=true $\& d b=e d b \& A N=96783710 \&$ site $=e d s$-live \&scope=site

Odumeru, J. a., \& Ifeanyi, G. O. (2013). Transformational vs. Transactional Leadership Theories: Evidence in Literature. Internationational Review of Management and Business Research, 2(2), 355-361.

Sadeghi, A. (2012). Transformational Leadership and Its Predictive Effects on Leadership Effectiveness. International Journal of Business \& Social Science, 3(7), 186-197.

Schafer, J. a. (2010). Effective leaders and leadership in policing: traits, assessment, development, and expansion. Policing: An International Journal of Police Strategies \& Management, 33(4), 644-663. http://doi.org/10.1108/13639511011085060

Scott, P. (2011). Leadership in universities. The International Journal of Leadership in Public Services, 7(3), 229-234. http://doi.org/10.1108/17479881111187051

Trocchia, P. J., \& Andrus, D. M. (2003). Perceived Characteristics and Abilities of an Effective Marketing Department Head. Journal of Marketing Education, 25(1), 5-15. http://doi.org/10.1177/0273475302250567

Wolverton, M., Ackerman, R., \& Holt, S. (2005). Preparing for Leadership: What Academic Department Chairs Need to Know. Journal of Higher Education Policy and Management, 27(2), 227-238. http://doi.org/10.1080/13600800500120126 